\title{
BMJ Open Perceived challenges to achieving universal health coverage: a cross- sectional survey of social health insurance managers/administrators in China
}

\author{
Linghan Shan, ${ }^{1}$ Qunhong Wu, ${ }^{1}$ Chaojie Liu, ${ }^{2}$ Ye Li, ${ }^{3}$ Yu Cui, ${ }^{1}$ Zi Liang, ${ }^{1}$ \\ Yanhua Hao, ${ }^{1}$ Libo Liang, ${ }^{1}$ Ning Ning, ${ }^{1}$ Ding Ding, ${ }^{1}$ Qingxia Pan, ${ }^{1}$ Liyuan $\operatorname{Han}^{4}$
}

To cite: Shan L, Wu Q, Liu C, et al. Perceived challenges to achieving universal health coverage: a cross-sectional survey of social health insurance managers/administrators in China. BMJ Open 2017;7:e014425. doi:10.1136/ bmjopen-2016-014425

- Prepublication history and additional material are available. To view these files please visit the journal online (http://dx.doi.org/ 10.1136/ bmjopen-2016-014425).

LS, YC and ZL contributed equally.

Received 24 September 2016 Revised 21 March 2017 Accepted 31 March 2017

CrossMark

${ }^{1}$ Department of Social Medicine, School of Public Health, Harbin Medical University, Harbin, Heilongjiang Province, China ${ }^{2}$ School of Psychology and Public Health, La Trobe University, Melbourne, Australia ${ }^{3}$ Department of Health Policy and Hospital Management,

School of Public Health, Harbin Medical University, Harbin, Heilongjiang Province, China ${ }^{4}$ Department of Preventive Medicine, School of Medical, Ningbo University, Ningbo, Zhejiang province, China

Correspondence to Professor Qunhong Wu; wuqunhong@163.com and Libo Liang; Ilbhit@163.com

\section{ABSTRACT}

Objective China has achieved over $96 \%$ health insurance coverage. However, universal health coverage (UHC) entails population coverage and the range of services covered and the extent to which health service costs are covered. This study aimed to determine the performance of the health insurance system in China in terms of its role in UHC and to identify challenges in the progress of UHC as perceived by health insurance managers/administrators.

Methods A cross-sectional questionnaire survey was conducted in Beijing, Ningbo, Harbin and Chongqing over the period of 2014 and 2015. A stratified cluster random sampling strategy was adopted to select study participants. A total of 1277 (64.8\%) respondents who reported familiarity with the current health insurance system and the requirements of UHC provided valid data for analyses. They gave a rating on the role of the current health insurance system in achieving UHC. A multivariate logistic regression model was developed to determine the associations between the rating and the features of insurance arrangements.

Results There was consensus among the respondents on the performance of the current health insurance system in terms of its role in UHC, regardless who they were and what responsibility they held in their organisation (ie, policy development, managing fund transactions, and so on). Overall, about $45 \%$ of the respondents believed that there is a long way to go to achieve UHC. The low rating was found to be associated with limited financial protection $(\mathrm{OR}=1.656,95 \% \mathrm{Cl} 1.279$ to 2.146$)$, healthcare inequity (OR=1.607, 95\% Cl 1.268 to 2.037), poor portability (OR=1.347, $95 \% \mathrm{Cl} 1.065$ to 1.703 ) and ineffective supervision and administration of funds $(\mathrm{OR}=1.339$, $95 \% \mathrm{Cl} 1.061$ to 1.692 ) as perceived by the respondents. Conclusion Health insurance managers/administrators in China are pessimistic about the achievements of the current health insurance system. They are concerned about the overall lack of benefit that insurance programmes bring to members, including low levels of entitlements, large healthcare inequity, limited financial protection and poor portability. A singular amendment of the structural design of the existing funds may not be enough to offer a satisfactory solution to these identified barriers. There is a need to increase funding capacities, to
Strengths and limitations of this study

- This study drew on the experiences of a wide range of health insurance managers/administrator. They are key stakeholders of healthcare reform. It is important to understand the views of those who develop policies and manage the daily transactions of funds.

- Although this study was undertaken in China, it can offer lessons to those countries that are expanding their health insurance programmes. It is important to note that a high coverage of health insurance is not enough. Insurance may stimulate healthcare consumptions, bringing disproportional negative consequences to the disadvantaged populations, especially when a high percentage of out-of-pocket payment is required. Equity needs to be considered in the design of insurance programmes. Effective and efficient management of fund is also important.

- Due to limited resources, the survey was conducted only in four cities. Despite the limitations, this study provided important information for understanding how insurance managers/administrators perceive the role and the challenges of health insurance in facilitating universal health coverage.

- In case the logistic regression modelling may not use some information, we also transformed the five categories of responses into three categories and performed proportional odds modelling using the ordered scale (results not presented in the text). The two modelling approaches generated consistent results.

develop unified and consistent policies and to increase the level of fund pooling.

\section{INTRODUCTION}

In 2005, the World Health Assembly issued a call on member states for universal health coverage (UHC), with an aim to achieve affordable and accessible medical care for 
all citizens. ${ }^{12}$ The Chinese government followed suit quickly and launched a series of health reforms. The first step in China's reforms involved an expansion of social health insurance coverage. Three basic health insurance schemes, Basic Medical Insurance for Urban Employees (BMIUE), Basic Medical Insurance for Urban Residents (BMIUR) and the New Rural Cooperative Medical Scheme (NCMS), were established to provide healthcare-related financial protection to more than 1.3 billion people. The BMIUE covers urban employees (including retired and rural-to-urban migrant workers), with both employees and employers contributing to the insurance funds. The contribution of an employee goes to an individual medical saving account, which cannot be used by other members, whereas the contribution of employers goes to a social pooling account managed at the municipal level. A member can choose to use his/her individual medical saving account to pay for medical expenses that are not covered by the social pooling account. ${ }^{3}$ The NCMS covers rural residents, with funding coming from government subsidies, collective assistance and individual contributions. The NCMS funds are pooled and managed at the county level. The BMIUR covers urban residents who are neither covered by the BMIUE nor the NCMS, such as the self-employed, the unemployed, the elderly, children and students. The BMIUR funds are pooled at the municipal level, with contributions from the individual members and government subsidies. While the BMIUE and BMIUR programmes are overseen by the Human Resources and Social Security authorities, the NCMS programme is largely left in the hands of the Health and Family Planning authorities. ${ }^{4-7}$ Technically, these three basic health insurance schemes are not always mandatory. However, because of strong governmental interventions and subsidies, a very high population coverage has been achieved. Although in some programmes, individual contribution goes to an individual saving account, the contribution of governments and employers (if exist) is put into a social pooling account with risk sharing functions. The membership eligibility, benefits and other aspects of those insurance programmes are also defined by the government. In China, they are labelled as social health insurance.

The rapid expansion of health insurance programmes in China has been extraordinary. Within a few years, about 96\% of Chinese people were covered by health insurance programmes. ${ }^{8}$ However, it is widely accepted that the high coverage of health insurance does not necessarily provide a guarantee of UHC. According to the WHO, UHC should consider the population coverage, the range of services covered and the extent to which health service costs are covered. ${ }^{910}$ Empirical evidence shows that people in China are still facing financial difficulties in managing illness. The funding level of health insurance has remained low despite a dramatic increase in governmental subsidies. ${ }^{11}$ The increase in medical expenditure exceeded the speed of wealth growth: from 2010 to 2013, the average annual growth of health expenditure reached $13.2 \%, 1.62$ times higher than the growth of gross domestic product (GDP) in the same period. ${ }^{12}$ This resulted in limited benefits and serious inequity. ${ }^{13-15}$ Catastrophic health expenses continue to haunt some people, especially the poor and disadvantaged. ${ }^{16-19}$

The international experience has demonstrated that a systems approach is needed to achieve UHC. ${ }^{20}$ Action should be guided by a well-linked structure, processes and outcomes measures. ${ }^{21}$ There is consensus that the achievements of UHC depend on an efficient, equitable and sustainable healthcare system that can maximise health gains. The ability of health insurance programmes to contribute to such a system is determined by many factors, such as financial capacity (or bargaining power) of the funds, risk-sharing arrangements, provider payment mechanisms, management of consumer claims and cooperation across funds. ${ }^{22-26}$

Despite extensive studies into the performance of social health insurance programmes in China, there is a paucity in the literature documenting how insurance managers/administrators perceive and act in response to the call for UHC. This study aimed to understand how insurance managers/administrators perceive the role of health insurance in facilitating UHC and to identify the challenges that may limit the full functioning of health insurance programmes. The study drew on the experiences of a wide range of health insurance managers/ administrators, from those who develop policies to those who manage the daily transactions of funds. The findings of this study may provide evidence to support improvements to the healthcare system in China and offer lessons to those countries that are expanding their health insurance programmes.

\section{METHODS}

\section{Sampling and data collection}

A cross-sectional questionnaire survey was conducted over the period of 2014 and 2015. The participants were selected through stratified cluster random sampling. We identified four municipalities, Beijing, Ningbo, Harbin and Chongqing, representing different levels of economic development in China (table 1, table 2). In each municipality, about $40 \%$ of the hospitals $(n=4 \sim 6), 20 \%$ of the social health insurance agencies $(n=2 \sim 3), 20 \%$ of the health authorities $(n=2 \sim 3), 10 \%$ of the research institutes $(\mathrm{n}=1 \sim 3)$ and $10 \%$ of the other relevant organisations (eg, health information centres, $\mathrm{n}=2 \sim 3$ ) were randomly selected. The sample size was estimated based on the need for logistic regression analyses: 10 times more than the number of independent variables. The number of participating organisations is proportional to the size of the selected municipalities.

All of the managers/administrators $(n=2010)$ who were working in the health insurance units were invited to participate in the survey. A total of 1971 of those invited completed the questionnaire. 'Do not have enough time' is the most common excuse for those who 
Table 1 Socioeconomic profiles of participating municipalities (2014)

\begin{tabular}{lllll}
\hline & Beijing & Ningbo & Harbin & Chongqing \\
\hline $\begin{array}{l}\text { Population } \\
\text { (million) }\end{array}$ & 21.51 & 7.81 & 10.63 & 29.91 \\
$\begin{array}{l}\text { GDP per } \\
\text { capita }\end{array}$ & $¥ 99995$ & $¥ 99210$ & $¥ 53925$ & $¥ 48031$ \\
$\begin{array}{l}\text { Average } \\
\text { salary }\end{array}$ & $¥ 77556$ & $¥ 48924$ & $¥ 51540$ & $¥ 56856$ \\
$\begin{array}{l}\text { Urban } \\
\text { average } \\
\text { disposable } \\
\text { income }\end{array}$ & $¥ 43910$ & $¥ 44155$ & $¥ 28815$ & $¥ 25147$ \\
$\begin{array}{l}\text { Rural average } \\
\text { net income }\end{array}$ & $¥ 20226$ & $¥ 24283$ & $¥ 12125$ & $¥ 8332$ \\
\hline
\end{tabular}

GDP, gross domestic product.

refused to participate in the survey. The respondents were asked whether they were familiar with the "current Chinese health insurance system' and the 'requirements of universal health coverage'. Those who reported 'very familiar' with both were eligible for the purpose of this study ( $\mathrm{n}=1291$, representing $65 \%$ of all 1971 respondents). A small number of returned questionnaires from these eligible respondents contained incomplete data and were therefore excluded from data analyses, which resulted in a final sample size of 1277 .

The questionnaire was administered through face-toface interviews. The interviewers were recruited from Harbin Medical University (including health service researchers and postgraduate research students) and participated in an intensive training workshop before embarking on the fieldwork. Each participant was interviewed by two interviewers. To ensure data quality, $5 \%$ of the respondents were randomly selected and revisited by a quality control officer. The results showed a high level $(96 \%)$ of consistency of data.

\section{Measurement}

The questionnaire was based on Donabedian's 'structure, process and outcomes' model ${ }^{19}$ and comprised five parts. Part one gathered information in relation to the demographic and socioeconomic characteristics of the participants, such as age, sex, city, educational attainment, working unit and work experience. Part two measured the expectations of the respondents on health insurance arrangements (outcomes) in achieving UHC. These include premium contributions, scope of services covered and consumer compensations. Part three tapped into the perceptions of the respondents about the structural design of health insurance programmes, such as financial sources, membership, provider payment, bargaining power and cooperation across funds. Part four measured the views of the respondents on the operations (process) management of consumer claims, such as processing procedures, supervision and administration, portability and overall use of funds. Part five asked the respondents to estimate the effectiveness (outcome) of an integrated insurance approach to UHC, such as financial protection, equity and cost control (online supplementary appendix S1).

\section{Data analysis}

We performed multivariate logistic regression analyses to identify the potential challenges existing in health insurance arrangements to achieving UHC.

\section{Dependent variable}

The overall rating of the respondents on the performance of the current Chinese health insurance system in relation to UHC was the major concern of this study. It was defined as a perceived gap between the performance (impact) of the current Chinese health insurance system and the requirements of UHC. The respondents were asked to answer the question using a 5-point Likert scale ( $1=$ =ery serious, $2=$ serious, $3=$ medium, $4=$ minor, $5=$ very minor): 'Think about the current health insurance system throughout the country. How would you rate the seriousness of the problems that have undermined the achievement of universal health coverage in general?' (table 3). The rating was collapsed into two categories: $1=$ 'serious' (including 'very serious' and 'serious') and $0=$ 'not serious' (including 'medium', 'minor' and 'very minor') for the purpose of logistic regression modelling.

\section{Independent variables}

\section{Expectations of health insurance arrangements}

The respondents were asked to choose from three options for their preferred premium arrangements: varied by income, varied by insurance package and equal contribution from members. Their anticipated level of reimbursement was set to range from $100 \%$ to $90 \%-99 \%$, $70 \%-89 \%$ and below $70 \%$. The respondents were also asked to choose their preferred benefit (compensation) design: medical treatment, medical treatment and preventive care, and medical treatment and preventive care plus fringe benefits (such as meals, lodging or transportation subsidies).

\section{Structural design of health insurance programmes}

The respondents were asked to answer the question, 'How do you feel about the structural design of health insurance in relation to the following aspects: enrolment, fee collection, provider payment, cross-fund cooperation and legal assurance'. Each aspect was assessed on a 10-point scale (ranging from totally irrational/incomplete to totally rational/complete). In the regression modelling, they were transformed into a dichotomous measurement and coded as $1=$ 'irrational/incomplete' and $0=$ 'rational/ complete'.

\section{Operations (process) management of consumer claims}

The respondents were asked to answer the question 'How do you feel about the management of consumer claims in relation to the following aspects: processing 
Table 2 Health insurance arrangements in participating municipalities (2014)

\begin{tabular}{|c|c|c|c|c|c|}
\hline & & Beijing & Ningbo & Harbin & Chongqing \\
\hline \multicolumn{6}{|c|}{ Premium contribution } \\
\hline \multirow[t]{2}{*}{ BMIUE } & Employer: & $10 \%$ salary & $9 \%$ salary & $6 \%$ salary & $8 \%$ salary \\
\hline & Self-employed: & - & - & - & $\begin{array}{l}¥ 1702.2 \text { without an } \\
\text { individual saving } \\
\text { account; } \\
¥ 3744.84 \text { with an } \\
\text { individual saving } \\
\text { account }\end{array}$ \\
\hline \multirow[t]{2}{*}{ BMIUR } & $\begin{array}{l}\text { Government } \\
\text { subsidy: }\end{array}$ & $¥ 1000$ per head & $\begin{array}{l}¥ 150^{*}, ¥ 200^{\dagger}, ¥ 400^{\ddagger}, \\
¥ 500^{\S} \text { or } ¥ 1800^{\uparrow}\end{array}$ & $\begin{array}{l}¥ 60^{\S, \dagger, *, \star \star}, ¥ 80^{\dagger \dagger}, \\
¥ 256^{\uparrow, \neq \ddagger} \text { or } ¥ 270 \ddagger\end{array}$ & $¥ 240$ per head \\
\hline & Individual: & $\begin{array}{l}¥ 160^{\S, t, *, \star \star}, ¥ 360^{\text {ๆ,㧊 }} \text { or } \\
¥ 660^{\ddagger}\end{array}$ & $\begin{array}{l}¥ 100^{\star, \dagger}, ¥ 400^{\S} \text { or } \\
¥ 600^{\ddagger, \uparrow}\end{array}$ & $\begin{array}{l}¥ 10^{\dagger \dagger}, ¥ 30^{\star, \dagger, \S, \star \star}, ¥ 60^{\ddagger} \\
\text { or } ¥ 65^{\uparrow, \neq \neq, \S \S}\end{array}$ & $¥ 60$ or $¥ 150$ \\
\hline NCMS & Individual: & $\geq ¥ 100$ & $\begin{array}{l}\text { Integrated with } \\
\text { BMIUR }\end{array}$ & $¥ 70$ & $\begin{array}{l}\text { Integrated with } \\
\text { BMIUR }\end{array}$ \\
\hline \multicolumn{6}{|c|}{ Deductible line } \\
\hline \multirow[t]{2}{*}{ BMIUE } & Outpatient: & $¥ 1800$ & $\begin{array}{l}¥ 500 \text { for retired; } \\
¥ 1000 \text { for over } \\
45 \text { years; } ¥ 1500 \text { for } \\
\text { under } 45 \text { years }\end{array}$ & -- & - \\
\hline & Inpatient: & $¥ 1300$ & $\begin{array}{l}¥ 800^{\text {ๆๆ }} \text {, } ¥ 1000^{\star \star *} \text { or } \\
¥ 1200^{\text {†† }}\end{array}$ & $\begin{array}{l}¥ 240^{\text {ๆl }}, ¥ 480^{\star * *} \text { or } \\
¥ 720^{\dagger+\dagger}\end{array}$ & $\begin{array}{l}¥ 200^{\text {ๆl }}: ¥ 440^{* \star *} \text { or } \\
¥ 880^{\dagger+t}\end{array}$ \\
\hline BMIUR & Outpatient: & $¥ 650$ & - & - & - \\
\hline NCMS & Inpatient: & $\begin{array}{l}¥ 300^{\text {ๆศी }}, ¥ 1000^{\star \star \star} \text { or } \\
¥ 1300^{\text {†十 }}\end{array}$ & $\begin{array}{l}\text { Integrated with } \\
\text { BMIUR }\end{array}$ & 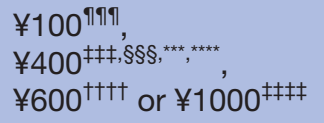 & $\begin{array}{l}\text { Integrated with } \\
\text { BMIUR }\end{array}$ \\
\hline
\end{tabular}

Reimbursement rate

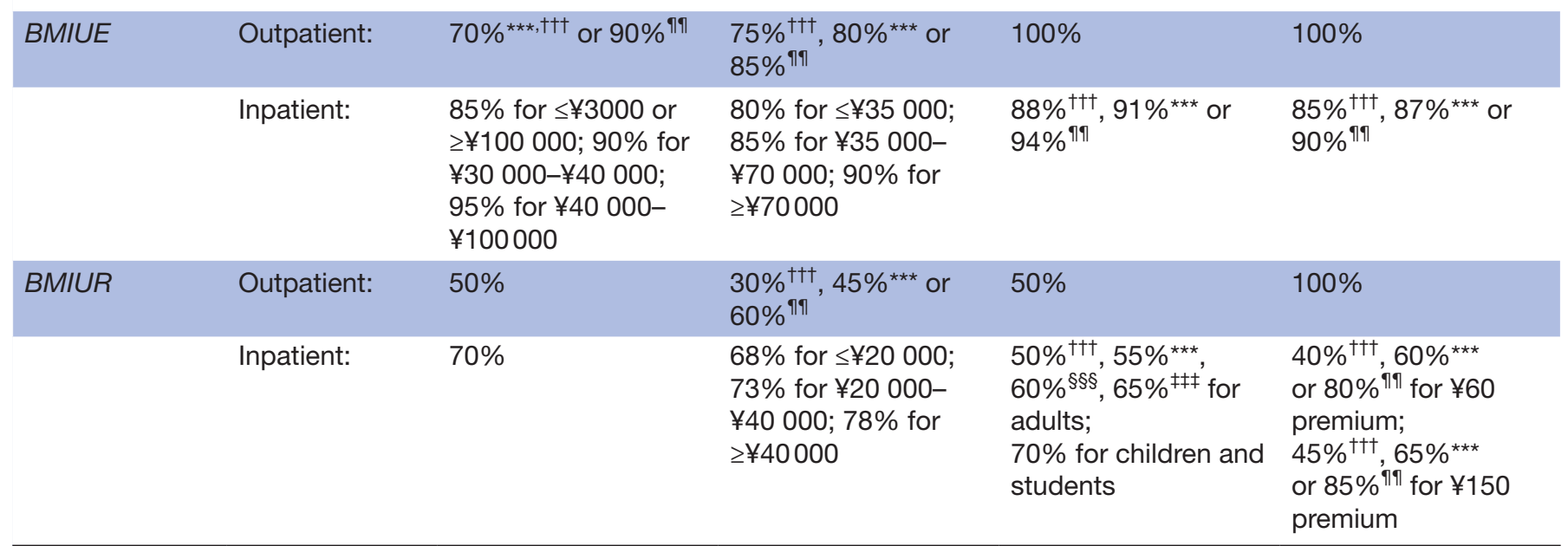


Table 2 Continued

\begin{tabular}{|c|c|c|c|c|c|}
\hline & & Beijing & Ningbo & Harbin & Chongqing \\
\hline NCMS & Outpatient: & $\begin{array}{l}30 \%{ }^{\dagger+\dagger c}, 40 \%{ }^{* \star *} \text { or } \\
55 \% \text { ๆท }\end{array}$ & $\begin{array}{l}\text { Integrated with } \\
\text { BMIUR }\end{array}$ & $90 \%$ & $\begin{array}{l}\text { Integrated with } \\
\text { BMIUR }\end{array}$ \\
\hline \multicolumn{6}{|c|}{ Maximum payouts } \\
\hline BMIUE & Inpatient: & $¥ 300000$ & - & $¥ 250000$ & $¥ 500000$ \\
\hline \multirow[t]{2}{*}{ BMIUR } & Outpatient: & $¥ 2000$ & $¥ 3000$ & $¥ 200$ & $¥ 60$ \\
\hline & Inpatient: & $¥ 170000$ & $¥ 250000$ & $¥ 110000$ & $\begin{array}{l}¥ 80000 \text { for } ¥ 60 \\
\text { premium; } \\
¥ 150000 \text { for } ¥ 150 \\
\text { premium }\end{array}$ \\
\hline NCMS & Inpatient: & $¥ 180000$ & $\begin{array}{l}\text { Integrated with } \\
\text { BMIUR }\end{array}$ & $¥ 80000$ & $\begin{array}{l}\text { Integrated with } \\
\text { BMIUR }\end{array}$ \\
\hline
\end{tabular}

${ }^{\star}$ For college students.

†For children 6-17 years old.

‡For unemployed.

$\S$ For children under 6 years.

ПFor elderly.

${ }^{* *}$ For non-college students.

††For poor or disabled children/students.

¥¥For disabled.

$\S \S$ For poor.

१ीFor primary hospitals.

***In secondary hospitals.

†††In tertiary hospitals.

$\ddagger \ddagger \ddagger$ In primary health institutions in urban communities.

$\S \S \S$ In primary hospitals in cities.

ๆๆๆIn appointed primary health institutions in townships.

${ }^{* * \star \star}$ In primary health institutions in counties.

$\dagger \dagger \dagger \dagger$ In tertiary hospitals at municipal level.

$\ddagger \ddagger \ddagger \ddagger l n$ tertiary hospitals at provincial level.

BMIUE, Basic Medical Insurance for Urban Employees; BMIUR, Basic Medical Insurance for Urban Residents; GDP, gross domestic product;

NCMS, New Rural Cooperative Medical Scheme.

procedure, fund usage, supervision and administration, legislation, portability, and bargaining power'. Similarly, each item was assessed on a 10-point scale (ranging from totally poor/cumbersome/ineffective to totally good/

Table 3 Ratings on the role of the current Chinese health insurance system for achieving universal health coverage $(n=1277)$

\begin{tabular}{lll}
\hline $\begin{array}{l}\text { Perceived gap in } \\
\text { performance }\end{array}$ & Frequency & Percentage (\%) \\
\hline Very serious & 252 & 19.7 \\
Serious & 319 & 25.0 \\
Medium & 587 & 46.0 \\
Minor & 113 & 8.8 \\
Very minor & 6 & 0.5 \\
\hline
\end{tabular}

convenient/effective) and then they were collapsed into a dichotomous measurement for modelling.

\section{Effectiveness (outcome) of an integrated insurance approach on UHC}

The respondents were asked to answer the question, 'How do you feel about the potential of an integrated insurance approach in relation to the following aspects: population coverage, financial protection, cost control, and equity'. Again, each item was assessed on a 10-point scale (ranging from totally ineffective to totally effective), and they were then collapsed into a dichotomous measurement for modelling.

\section{Control variables}

We controlled the confounding influence of demographic and socioeconomic characteristics (age, sex, city, 
education, working unit and work experience) of the respondents in the statistical analyses.

\section{Statistical analysis}

Data were analysed using SPSS V.21.0. We performed $\chi^{2}$ tests to determine the inclusion of independent and control variables in the logistic modelling. Those with a significant association with the overall rating on the health insurance system in the $\chi^{2}$ tests $(\mathrm{p}<0.05)$ were entered into the logistic regression models (method=" ENTER', entry='0.05', removal='0.10').

We also transformed the five categories of responses into three categories (serious, medium and minor) and performed proportional odds modelling using the ordered scale. The two modelling approaches generated consistent results. For simplicity, we only presented the results of the logistic regression models.

\section{Ethics approval}

The study protocol was reviewed and approved by the Research Ethics Committee of Harbin Medical University.

\section{RESULTS}

\section{Characteristics of respondents}

More than half of the respondents were women (59.4\%) and were aged between 30 and 44 years $(59.4 \%)$. The majority $(81.6 \%)$ had completed tertiary education. About $58 \%$ had worked more than 10 years at the time of the survey. Respondents from hospitals comprised $40.3 \%$ of all respondents.

\section{Ratings on health insurance}

Overall, $44.7 \%$ of respondents believed that serious problems exist in the current Chinese health insurance system which undermined the achievement of UHC (table 3). The rating of the performance of the current health insurance system was found to be significantly associated with the educational attainments of the respondents, and their expectations of and perceived rationality and impacts of the health insurance system (table 4). The respondents who had obtained a doctoral degree; those who preferred a broader scope of coverage (including medical treatment and preventive care, or medical treatment and preventive care plus fringe benefits); who felt disappointed with the insurance programmes (regarding its provider payment, bargaining power and legal assurance); who criticised the operations management (in its supervision and administration of funds and portability of entitlements); and those who perceived lower levels of the impact of health insurance programmes (in its financial protection, cost containment, and healthcare equity) were more likely to rate the role played by the current health insurance system in achieving UHC as low. However, no differences in the performance rating were found between those who engaged in different tasks at different settings, those who worked in different cities and those who had different expectations of the share of financial contributions and benefits of the insurance programmes.

The logistic regression model identified four significant predictors $(\mathrm{p}<0.05)$ of the low rating for health insurance after controlling for confounding factors: perceived low impacts of health insurance on financial protection $(\mathrm{OR}=1.656)$ and healthcare equity $(\mathrm{OR}=1.607)$, poor portability of entitlements $(\mathrm{OR}=1.347)$ and ineffective supervision and administration of funds $(\mathrm{OR}=1.339)$. The variables in relation to the characteristics of the respondents and the structural design of the insurance programmes were statistically insignificant in the model (table 5).

\section{Perceived reasons for low ratings on health insurance}

Of those who gave a negative rating on the current health insurance system in terms of its role in UHC $(n=571)$, $76.1 \%$ blamed the low level of entitlements (reimbursement rate), $72.7 \%$ believed that the benefit packages failed to meet the needs of patients, $66 \%$ criticised the identity-linked insurance schemes and geographic variations for exacerbating healthcare inequity and 53.9\% identified the poor portability of entitlements as a major constraint in achieving UHC. These respondents were also critical of the operations management of the insurance programmes, with $58.7 \%$ attributing inefficient management as a reason for poor insurance performance, compared with $49.2 \%$ blaming the ineffective control of soaring medical costs, $41.4 \%$ blaming the cumbersome claim processing procedures,and $38.9 \%$ blaming the shortage of a tiered referral mechanism (figure 1).

\section{Discussion}

There was consensus among the respondents on the performance of the current health insurance system in terms of its role in UHC regardless of who they were and what responsibilities they held in their organisation. Overall, about $45 \%$ of the respondents believed that there is a long way to go to achieve UHC despite nearly total universal health insurance coverage in China. ${ }^{27} 28$ The low ratings on the performance of the insurance programmes remain consistent among those who have different demographic characteristics and work experience, and between those who develop policies and those who manage daily transactions.

The health insurance managers/administrators were overwhelmingly concerned about the actual benefits that the insurance programmes are able to offer their members, such as financial protection, healthcare equity, effective use of funds and portability of entitlements. However, it seems that they tended not to associate the shortage of achievements with the structural design of those insurance programmes. No differences were found in the ratings of those who had different preferences on the structural design of the insurance programmes, such as how individuals contribute to the funds and what percentage of medical expenses is reimbursed. Clearly, the respondents were more concerned about the overall 
Table 4 Factors associated with ratings of respondents on the performance of the current Chinese health insurance system $(n=1277)$

\begin{tabular}{|c|c|c|c|c|}
\hline Characteristics of respondents & n (\%) & $\begin{array}{l}\text { Rated with serious } \\
\text { problems (\%) }\end{array}$ & $\chi^{2}$ & p Value \\
\hline Sex & & & 0.483 & 0.487 \\
\hline Male & $519(40.6)$ & $226(43.5)$ & & \\
\hline Female & $758(59.4)$ & $345(45.5)$ & & \\
\hline Age (years) & & & 1.299 & 0.729 \\
\hline$<30$ & $171(13.4)$ & $82(48.0)$ & & \\
\hline $30-44$ & $759(59.4)$ & $340(44.8)$ & & \\
\hline $45-59$ & $303(23.7)$ & $129(42.6)$ & & \\
\hline$\geq 60$ & $44(3.4)$ & $20(45.5)$ & & \\
\hline Level of education & & & 8.116 & 0.044 \\
\hline Without a tertiary degree & $234(18.3)$ & $96(41.0)$ & & \\
\hline University undergraduate degree & $764(59.8)$ & $340(44.5)$ & & \\
\hline Master's degree & $215(16.8)$ & $96(44.7)$ & & \\
\hline Doctoral degree & $64(5.0)$ & $39(60.9)$ & & \\
\hline Working experience (years) & & & 5.519 & 0.063 \\
\hline$<5$ & $262(20.5)$ & $134(51.1)$ & & \\
\hline $5-9$ & $280(21.9)$ & $121(43.2)$ & & \\
\hline$\geq 10$ & $735(57.6)$ & $316(43.0)$ & & \\
\hline Working unit & & & 2.086 & 0.720 \\
\hline Hospitals & $514(40.3)$ & $236(45.9)$ & & \\
\hline Health authority & $274(21.5)$ & $121(44.2)$ & & \\
\hline Social insurance agency & $281(22.0)$ & $118(42.0)$ & & \\
\hline Research institute & $106(8.3)$ & $52(49.1)$ & & \\
\hline Others & $102(8.0)$ & $44(43.1)$ & & \\
\hline City & & & 6.829 & 0.078 \\
\hline Beijing & $358(28.0)$ & $151(42.2)$ & & \\
\hline Ningbo & $265(20.8)$ & $122(46.0)$ & & \\
\hline Harbin & $314(24.6)$ & $158(50.3)$ & & \\
\hline Chongqing & $340(26.6)$ & $571(44.7)$ & & \\
\hline \multicolumn{5}{|l|}{ Expectations of insurance arrangements } \\
\hline Individual contribution & & & 0.705 & 0.703 \\
\hline Varied by income & $263(20.6)$ & $112(42.6)$ & & \\
\hline Varied by insurance packages & $434(34.0)$ & $194(44.7)$ & & \\
\hline Equal contributions from members & $580(45.4)$ & $265(45.7)$ & & \\
\hline Reimbursement rate & & & 1.331 & 0.722 \\
\hline $100 \%$ & $338(26.5)$ & $159(47.0)$ & & \\
\hline $90 \%-99 \%$ & $671(52.5)$ & $296(44.1)$ & & \\
\hline $70 \%-89 \%$ & $242(19.0)$ & $106(43.8)$ & & \\
\hline$<70 \%$ & $26(2.0)$ & $10(38.5)$ & & \\
\hline Scope of covered services & & & 6.329 & 0.042 \\
\hline $\begin{array}{l}\text { Medical treatment and preventive care plus fringe } \\
\text { benefits }\end{array}$ & $378(29.6)$ & $184(48.7)$ & & \\
\hline Medical treatment and preventive care & $616(48.2)$ & $277(45.0)$ & & \\
\hline Medical treatment only & $283(22.2)$ & $110(38.9)$ & & \\
\hline Structural design of health insurance programme & & & & \\
\hline
\end{tabular}

Continued 
Open Access

Table 4 Continued

\begin{tabular}{|c|c|c|c|c|}
\hline Characteristics of respondents & n (\%) & $\begin{array}{l}\text { Rated with serious } \\
\text { problems (\%) }\end{array}$ & $\chi^{2}$ & p Value \\
\hline Enrolment & & & 3.488 & 0.062 \\
\hline Rational & $515(40.3)$ & $214(41.6)$ & & \\
\hline Financial sources & & & 0.525 & 0.469 \\
\hline Rational & $770(60.3)$ & $338(43.9)$ & & \\
\hline Provider payment & & & 3.923 & 0.048 \\
\hline Irrational & $892(69.9)$ & $415(46.5)$ & & \\
\hline Rational & $385(30.1)$ & $156(40.5)$ & & \\
\hline Cooperation across funds & & & 1.247 & 0.264 \\
\hline Incomplete & $852(66.7)$ & $398(46.7)$ & & \\
\hline Complete & 425 (33.3) & $173(40.7)$ & & \\
\hline \multicolumn{5}{|l|}{ Operations management of patient claims } \\
\hline Processing procedure & & & 2.632 & 0.105 \\
\hline Cumbersome & $742(58.1)$ & $346(46.6)$ & & \\
\hline Convenient & $535(41.9)$ & $225(42.1)$ & & \\
\hline Use of funds & & & 3.193 & 0.074 \\
\hline Ineffective & $741(58.0)$ & $347(46.8)$ & & \\
\hline Good & $465(36.4)$ & $191(41.1)$ & & \\
\hline Portability of entitlement & & & 6.371 & 0.012 \\
\hline Poor & $774(60.6)$ & $368(47.5)$ & & \\
\hline Good & $503(39.4)$ & $203(40.4)$ & & \\
\hline \multicolumn{5}{|l|}{ Perceived impacts of health insurance } \\
\hline Population coverage & & & 2.204 & 0.138 \\
\hline Not universal & $134(10.5)$ & $68(50.7)$ & & \\
\hline Universal & $1143(89.5)$ & $503(44.0)$ & & \\
\hline Financial protection & & & 16.581 & 0.000 \\
\hline Ineffective & $918(71.9)$ & $443(48.3)$ & & \\
\hline Effective & $359(28.1)$ & $128(35.7)$ & & \\
\hline Cost containment & & & 4.486 & 0.034 \\
\hline Ineffective & $748(58.6)$ & $353(47.2)$ & & \\
\hline Effective & $529(41.4)$ & $218(41.2)$ & & \\
\hline Healthcare equity & & & 17.697 & 0.000 \\
\hline Ineffective & $768(60.1)$ & $380(49.5)$ & & \\
\hline Effective & 509 (39.9) & 191 (37.5) & & \\
\hline
\end{tabular}


Table 5 Predictors of low ratings on the performance of the current Chinese health insurance system: findings from logistical regression modelling

\begin{tabular}{|c|c|c|c|}
\hline Variables & OR & \multicolumn{2}{|l|}{$95 \% \mathrm{Cl}$} \\
\hline \multicolumn{4}{|l|}{ Level of education } \\
\hline $\begin{array}{l}\text { University undergraduate } \\
\text { degree }\end{array}$ & 1.041 & 0.766 & 1.416 \\
\hline Master's degree & 1.029 & 0.700 & 1.515 \\
\hline Doctoral degree & 2.164 & 1.206 & 3.885 \\
\hline $\begin{array}{l}\text { Without a tertiary degree } \\
\text { (reference) }\end{array}$ & & & \\
\hline
\end{tabular}

Expectations of insurance

arrangements

\begin{tabular}{|c|c|c|c|}
\hline \multicolumn{4}{|l|}{ Scope of covered services } \\
\hline $\begin{array}{l}\text { Medical treatment and } \\
\text { preventive care plus fringe } \\
\text { benefits }\end{array}$ & 1.488 & 1.077 & 2.055 \\
\hline $\begin{array}{l}\text { Medical treatment and } \\
\text { preventive care }\end{array}$ & 1.290 & 0.960 & 1.735 \\
\hline \multicolumn{4}{|l|}{$\begin{array}{l}\text { Medical treatment only } \\
\text { (reference) }\end{array}$} \\
\hline \multicolumn{4}{|l|}{$\begin{array}{l}\text { Structural design of health } \\
\text { insurance programmes }\end{array}$} \\
\hline \multicolumn{4}{|l|}{ Provider payment } \\
\hline Irrational & 1.256 & 0.976 & 1.617 \\
\hline \multicolumn{4}{|l|}{ Rational (reference) } \\
\hline \multicolumn{4}{|l|}{ Legal assurance } \\
\hline Incomplete & 1.268 & 0.994 & 1.618 \\
\hline Complete (reference) & & & \\
\hline
\end{tabular}

Operations management of

patient claims

\begin{tabular}{llll}
$\begin{array}{l}\text { Supervision and administration } \\
\text { of funds }\end{array}$ & & & \\
$\quad$ Ineffective & 1.339 & 1.061 & 1.692 \\
\hline $\begin{array}{l}\text { Effective (reference) } \\
\text { Bargaining power }\end{array}$ & 1.221 & 0.961 & 1.551 \\
\hline Poor & & & \\
$\quad$ Good (reference) & & & \\
\hline $\begin{array}{l}\text { Portability of entitlements } \\
\text { Poor }\end{array}$ & 1.347 & 1.065 & 1.703 \\
\hline Good (reference) & & & \\
\hline
\end{tabular}

Perceived impacts of health

insurance

\begin{tabular}{llll} 
Financial protection & 1.656 & 1.279 & 2.146 \\
\hline Ineffective & & & \\
Effective (reference) & & & \\
Cost containment & 1.255 & 0.992 & 1.589 \\
\hline Ineffective & & & \\
Effective (reference) & & \\
Healthcare equity & & \\
\hline
\end{tabular}

Continued
Table 5 Continued

\begin{tabular}{lcll}
\hline Variables & OR & $\mathbf{9 5 \%} \mathbf{C l}$ & \\
\hline Ineffective & 1.607 & 1.268 & 2.037 \\
Effective (reference) & & & \\
Constants & 0.121 & & \\
\hline
\end{tabular}

capacity of the insurance programmes. This is understandable because overall, the available funds are limited and individual contributions are low. In 2013, the BMIUR and NCMS had, on average, $¥ 450$ and $¥ 410$ of funding per member, respectively, but the average per capita health expenditure reached $¥ 2300$ ( 1 dollar $=6.3125$ RMB on average).$^{29}$ Due to limited funds, many services have been deliberately excluded from insurance claims. These include, but are not limited to, prevention-oriented services $^{30}$ such as the management of chronic conditions and routine physical examinations, which is a great financial burden for many consumers. ${ }^{31}$ In addition, once their hospital bills exceed a certain level (usually about six times the local average salary or disposable/net income), patients have to pay the remainder from their own pockets. ${ }^{32}$

Challenges to UHC

Limited financial protection

A lack of capacity to offer effective financial protection was identified as the most important challenge hindering the achievement of UHC. Indeed, financial protection has been considered a crucial element of universal health coverage. ${ }^{33-36}$ We found that the odds of low ratings on health insurance by those who perceived ineffective financial protection was 1.66 times of those who perceived effective financial protection. More than $72 \%$ of the respondents who gave a low rating on health insurance believed that the insurance programmes have failed to meet the needs of members.

These results are consistent with the findings of other studies. In a recent commentary, Yip and Hsiao ${ }^{8}$ claimed that the financial protection function of the current Chinese health system remains insufficient. ${ }^{16}$ According to the WHO global health expenditure database, ${ }^{37}$ out-ofpocket payments in China amounted to $32 \%$ of the total health expenditure in 2014, which is much higher than the level $(15 \%-20 \%)$ recommended by the WHO. ${ }^{38}$ Empirical evidence shows that the high level of out-ofpocket payments in China has resulted in catastrophic health expenditure and the medical impoverishment of the poor and disadvantaged. ${ }^{16}$ At the 2013 National Health Conference, Dr Zhu Chen, former health minister, admitted that the actual compensation rate of health insurance programmes in China was $50 \%$, which is lower than the announced average of $75 \% .^{39}$

Despite the many thorny problems and challenges, we must admit that it was an incredible achievement of China, to reach above $96 \%$ coverage of health insurance in such a short period of time. However, the following 


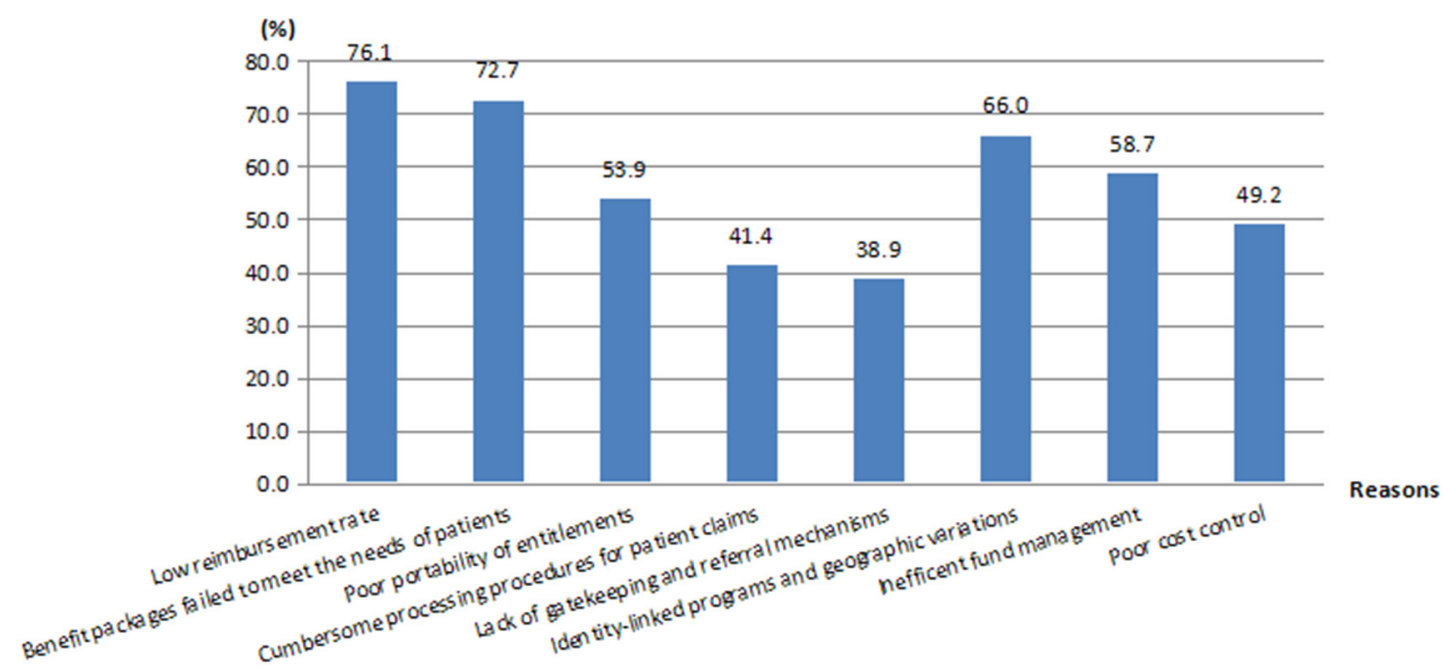

Figure 1 Perceived reasons for low ratings on health insurance.

issues must be addressed to further progress towards UHC. Increasing government investment is needed. Insufficient funding is an underlying cause of the major concerns (high level of out-of-pocket payment and insufficient benefit package) raised by the survey respondents. Currently, government spending on health in China accounts for only $3.1 \%$ of GDP, which is much lower than the world average $5.99 \%$ in $2014 .{ }^{40}$ According to a group of health economists convened by Chatham House, governments should commit to spending at least $5 \%$ of GDP on health in order to achieve UHC. ${ }^{41}$ This suggests that there is still some space for improvement. China may be able to succeed in UHC with increased public financial support, budget transfers and subsidies.

\section{Healthcare inequity}

Healthcare inequity is another major concern expressed by the respondents. A needs-based equal access system is the fundamental goal of UHC. We found that the odds of low ratings on health insurance by those who perceived a lack of influence of insurance on healthcare equity was 1.60 times of those who perceived a positive role of the insurance programmes.

Obviously, the health insurance system itself has contributed, at least in part, to the increasing healthcare inequity. About $66 \%$ of the respondents who gave a low rating on health insurance programmes criticised the multiple insurance policies for exacerbating healthcare inequity. The current Chinese health insurance system comprises three mutually exclusive schemes-BMIUE, BMIUR and NCMS. Previous studies have demonstrated that significant entitlement disparities exist among the three schemes. BMIUE members enjoy the highest level of entitlements compared with members of the other two schemes. These include larger available funds, broader scope of services covered and higher compensation rates. ${ }^{42}$ Even within the same insurance scheme, richer members may also benefit more than their poorer counterparts due to barriers imposed by the requirements of out-of-pocket payments. The National Urban Health Insurance Household Survey (2007-2011) revealed that $40 \%$ of medical expenditure was covered by health insurance for the highest income group compared with only $28 \%$ for the lowest income group in BMIUR. ${ }^{43}$ Another study found that the NCMS actually enlarged income-related inequality in the prevalence of catastrophic health expenditure. ${ }^{44}$ Regional differences further compound healthcare inequity. Large regional disparities in economic development and health insurance arrangements exist in China. ${ }^{45} 46$

\section{Poor portability of entitlements}

A lack of portability of entitlements of health insurance programmes was perceived as one of the barriers to achieving UHC. We found that the odds of low ratings on health insurance by those who perceived poor portability was 1.35 times of those who perceived good portability. About $54 \%$ of the respondents who gave a low rating on health insurance believed that poor portability has hindered the progress of UHC. In China, most health insurance funds have been set up and managed at the city or county level. Only six provinces (out of 31 provinces) have allowed insurance members to receive a healthcare service and to also receive compensation outside their home cities/counties, ${ }^{47}$ although with a lower level of benefits. The great variations across health insurance programmes in terms of premiums, benefit packages and reimbursement and the lack of information system support have imposed a serious barrier on the effort to increase the portability of insurance entitlements.

The poor portability of insurance entitlements runs counter to the trend of increased population mobility. With rapid industrialisation and urbanisation, floating populations in China reached 2.53 billion by the end of $2014{ }^{48}$ However, many of them were insured with their home counties/cities. The low accessibility of floating populations to their insurance funds has attracted increasing concerns from the society. ${ }^{49} 50$ 
Ineffective supervision and administration of funds

A good supervisory and administration system is essential for insurance funds to be effective in achieving UHC. ${ }^{5152}$ We found that those who felt disappointed with fund administration were more likely $(\mathrm{OR}=1.34)$ to give a low rating on the performance of insurance programmes compared with those who reported positively on the supervisory and administration system.

The current management system for the health insurance programmes is highly fragmented and inefficient. There is a lack of universal and consistent policies for claim management. While the BMIUE and BMIUR schemes are overseen and managed by the Human Resources and Social Security authority, the NCMS scheme remains a responsibility of the health authority. Coordination across these schemes is extremely challenging, diminishing the bargaining power of the insurance authorities. The lack of coordination also creates wastage in infrastructure development. $^{425354}$

\section{Limitation}

Due to limited resources, the survey was conducted only in four cities. Despite the limitations, this study provided important information for understanding how insurance managers perceive the role and the barriers of health insurance in facilitating UHC to support the development of healthcare system in China, and offer lessons to those countries that are expanding their health insurance programmes.

In case the logistic regression modelling may not use some information, we also transformed the five categories of responses into three categories and performed proportional odds modelling using the ordered scale (results not presented in the text). The two modelling approaches generated consistent results. The logistic models match well with the purpose of our study: to understand how insurance managers/administrators perceive the role of health insurance in facilitating UHC and to identify the challenges that may limit the full functioning of health insurance programmes.

\section{Conclusion and policy recommendations}

Health insurance managers in China are pessimistic about the achievements of the current health insurance system. They are concerned about the overall benefits that the insurance programmes can bring to members. Low levels of entitlements, large healthcare inequality, limited financial protection and poor portability are deemed as major challenges in the progress of UHC.

It is important to note that amendments to the structural design of the existing funds may not be enough to offer a satisfactory solution to these identified barriers. According to the perceptions of the health insurance managers, increasing funding capacity may be more important than singular adjustments of the share of premium contributions and the level of defined compensation. Increasing government investment in health is a necessary condition for improving finical protection. The findings also indicate that unified and consistent policies are required to reduce healthcare inequalities within and across funds. Although it is too early to conclude that a national approach is needed, a higher level of fund pooling will definitely bring benefits to improved portability, a better share of financial risks and more efficient operations management of funds. In recent years, there have been calls for the establishment of transitional funds at the provincial or national level, providing additional support to the poor and disadvantaged. ${ }^{425355}$

For those countries that are expanding their health insurance programmes, it is important to note that a high coverage of health insurance is not enough. Insurance may stimulate healthcare consumptions, bringing disproportional negative consequences to the disadvantaged populations, especially when a high percentage of out-of-pocket payment is required. Equity needs to be considered in the design of insurance programmes. Effective and efficient management of fund is also important.

\section{SUPPORTING INFORIMATION}

See online supplementary appendix. Questionnaire

Correction notice This paper has been amended since it was published Online First. Owing to a scripting error, some of the publisher names in the references were replaced with 'BMJ Publishing Group'. This only affected the full text version, not the PDF. We have since corrected these errors and the correct publishers have been inserted into the references.

Acknowledgements The authors would like to thank all the participants in this study.

Contributors Conceived and designed the study: QW, LL, YH and LS. Collected the data: LS, QW, LL, ZL, YC, YH, NN, YL, DD, QP and LH. Analysed the data: LS, ZL and YC. Wrote the manuscript: LS, ZL and YC. Revised the manuscript: LS, QW, LL, CL, ZL and YL. LS, ZL and YC contributed equally.

Funding This work was supported by the National Natural Science Fund (71333003, 71403073).

Competing interests None declared.

Provenance and peer review Not commissioned; externally peer reviewed. Data sharing statement № additional unpublished data are available.

Open Access This is an Open Access article distributed in accordance with the Creative Commons Attribution Non Commercial (CC BY-NC 4.0) license, which permits others to distribute, remix, adapt, build upon this work non-commercially, and license their derivative works on different terms, provided the original work is properly cited and the use is non-commercial. See: http://creativecommons.org/ licenses/by-nc/4.0/

(c) Article author(s) (or their employer(s) unless otherwise stated in the text of the article) 2017. All rights reserved. No commercial use is permitted unless otherwise expressly granted.

\section{REFERENCES}

1. World Health Organization. Sustainable health financing, universal coverage and social health insurance. Geneva, Switzerland: World Health Assembly Resolution, 2005.

2. Carrin G, James C. Reaching universal coverage via social health insurance: key design features in the transition period. Geneva, Switzerland: World Health Organization, 2004.

3. State Council. State Council Policy Document 1998 No. 44, Decisions of the State Council on the Establishment of Urban Employee Medical Insurance System

4. State Council. State Council Policy Document 2007 No. 20, Pilot Reforms on Developing Urban Resident Basic Medical Insurance, 2007. 
5. State Council. State Council Policy Document 2002 No. 13, Decisions of the State Council on Strengthening Rural Healthcare, 2002.

6. State Council. State Council Policy Document 2003 No.3, Guidelines on the Enrollment of Urban Workers in Flexible Employment in Basic Medical Insurance.

7. State Council. State Council Policy Document 2003 No. 3, The Opinions on the Establishment of New Rural Cooperative Medical System, 2003.

8. Yip W, Hsiao W. Harnessing the privatisation of China's fragmented health-care delivery. Lancet 2014;384:805-18.

9. World Health Organization. Strategy on health care financing for countries of the Western Pacific and South-East Asia Regions (20062010). Manila: WHO Regional Office for the Western Pacific, 2005.

10. World Health Organization. The World Health Report 2008: primary health care-now more than ever. Geneva, Switzerland: World Health Organization, 2000.

11. Sun ZG. Three basic health insurance coverage over $95 \%$ to promote the immediate settlement of medical insurance in different places. http://news.xinhuanet.com/politics/2013-08/07/c_116837861_2.htm (accessed September 1, 2016).

12. Fang P. Report on the development of China's Medical and Health Services in 2014. Beijing: People's publishing house, 2015.

13. Flatø $\mathrm{H}$, Zhang $\mathrm{H}$. Inequity in level of healthcare utilization before and after universal health coverage reforms in China: evidence from household surveys in Sichuan Province. Int J Equity Health 2016;15:1-12.

14. Pan J, Tian S, Zhou Q, et al. Benefit distribution of social health insurance: evidence from China's urban resident basic medical insurance. Health Policy Plan 2016;31:853-9.

15. Meng Q, Xu L. Monitoring and evaluating progress towards Universal Health Coverage in China. PLoS Med 2014;11:e1001694.

16. Li Y, Wu Q, Xu L, et al. Factors affecting catastrophic health expenditure and impoverishment from medical expenses in China: policy implications of universal health insurance. Bull World Health Organ 2012;90:664-71.

17. Li Y, Wu Q, Liu C, et al. Catastrophic health expenditure and rural household impoverishment in China: what role does the new cooperative health insurance scheme play? PLoS One 2014;9:e93253.

18. Xin X-X, Guan X-D, Shi L-W. Catastrophic expenditure and impoverishment of patients affected by 7 rare diseases in China. Orphanet J Rare Dis 2016;11:1-7.

19. Jan S, Lee SW, Sawhney JP, et al. Catastrophic health expenditure on acute coronary events in Asia: a prospective study. Bull World Health Organ 2016;94:193-200.

20. World Health Organization. Health workforce and services: draft global strategy on human resources for health: workforce 2030. Geneva, Switzerland: World Health Organization, 2015.

21. Donabedian A. The quality of care. How can it be assessed? JAMA $1988 ; 26012$.

22. Sachs JD. Achieving universal health coverage in low-income settings. Lancet 2012;380:944-7.

23. Wong J. Achieving universal health coverage. Bull World Health Organ 2015;93:663-4.

24. Nay O, Béjean S, Benamouzig D, et al. Achieving universal health coverage in France: policy reforms and the challenge of inequalities. Lancet 2016;387:2236-49.

25. Tangcharoensathien $\mathrm{V}$, Limwattananon S, Patcharanarumol W, et al. Achieving universal health coverage goals in Thailand: the vital role of strategic purchasing. Health Policy Plan 2015;30:1152-61.

26. World Health Organization. Financing for Universal Health Coverage. Geneva, Switzerland: World Health Report, 2010.

27. Meng Q, Xu L, Zhang Y, et al. Trends in access to health services and financial protection in China between 2003 and 2011: a crosssectional study. Lancet 2012;379:805-14.

28. China healthcare briefing in 2009. Beijing: Ministry of Health in China 2010.

29. Jq W, Bin L. Next year to continue to improve the level of funding for urban and rural residents. http://legal.people.com.cn/n/2014/1229/ c42510-26289236.html.

30. National Health and Family Planning Commission of China. Why the basic medical insurance "From the key security illness started, gradually extended to the clinic for minor illnesses". http://www .nhfpc.gov.cn/tigs/s9664/200904/e4c2a9d9fd6142aebb1ba8420f 169838.shtml (accessed September 1, 2016).

31. Chen J, Zhang K, Tao Y. Canonical correlation analysis on Hospital costs and Medical Insurance reimbursement of common chronic disease. Chinese General Practice 2013;16:4081-4.
32. Braun K. Social Security Explained. http://www.michigancapitolcon fidential.com/12617 (accessed December 5, 2016).

33. Saksena P, Hsu J, Evans DB. Financial risk protection and universal health coverage: evidence and measurement challenges. PLoS Med 2014;11:e1001701.

34. Nicholson D, Yates R, Warburton W, et al. Delivering universal health coverage: a guide for policymakers. Report of the WISH Universal Health Coverage Forum 2015 http://www.wish-qatar.org/app/media/ download/1431 (accessed November 26, 2016).

35. Chan M. WHO Director-General addresses ministerial meeting on universal health coverage. http://www.who.int/dg/speeches/2015/ singapore-uhc/en/ (accessed November 30, 2016).

36. Roberts M, Hsiao W, Berman P, et al; Getting health reform right: a guide to improving performance and equity. New York: Oxford university press, 2003.

37. World Health Organization. Global Health expenditure database. http://apps.who.int/nha/database (accessed June 28, 2016).

38. World Health Organization. Draft global health sector strategy on viral hepatitis, 2016-2021-the first of its kind. Geneva, Switzerland: World Health Organization, 2015.

39. Bai JF. Health minister admitted that the medical treatment is difficult, expensive, there is no fundamental solution. http://politics. people.com.cn/n/2013/0108/c1001-20124998.html (accessed September 1, 2016).

40. Bank W. Health expenditure, public (\% of GDP). Washington, DC: World Bank, 2014. http://data.worldbank.org/indicator/SH.XPD. PUBL.ZS?end=2014\&start=2014\&view=bar\&year=2014. (accessed December 2, 2016).

41. Rottingen JA, Ottersen T, Ablo A, et al; Shared responsibilities for health: a coherent global framework for health financing; final report of the Centre on Global Health Security Working Group on Health Financing. London: The Royal Institute of International Affairs, 2014.

42. Bank W, report $\mathrm{M}$. The path to integrated insurance system in China (Vol. 2):Main report. Washington, DC: World Bank, 2010. http:// documents.worldbank.org/curated/en/926821468024660940/Mainreport. (accessed September 1, 2016).

43. Tian S, Zhou Q, Pan J. Inequality in social health insurance programmes in China: a theoretical approach. Journal of Asian Public Policy 2015;8:56-68.

44. Ma J, Xu J, Zhang Z, et al. New cooperative medical scheme decreased financial burden but expanded the gap of income-related inequity: evidence from three provinces in rural China. Int J Equity Health 2016;15:72-3.

45. Huang X, 2011. Regional differences in China's current medical insurance: a survey report of 7 Province of 2011. The Seventh Session of the International Forum on Social Policy, Guangzhou 460-7.

46. Sun S, Chen J, Johannesson M, et al. Regional differences in health status in China: population health-related quality of life results from the National Health Services Survey 2008. Health Place 2011;17:671-80.

47. Zhou N. The Ministry of Human Resources and Social Security held a press conference in the third quarter. http://www.gov.cn/xinwen/ 2015-10/27/content_5001639.htm (accessed September 1, 2016).

48. National Health and Family Planning Commission of China. Report on the development of China's floating population 2015 http://news. 10jqka.com.cn/20151112/c585812370.shtml (accessed September 1, 2016).

49. Lei Y. Hu Xiaoyi: remote medical reimbursement is a fairly comprehensive problem. http://news.china.com.cn/2015lianghui/ 2015-03/10/content_35008692.htm (accessed September 1, 2016).

50. Barber S, Lan Y. Health insurance systems in China: a briefing note. Geneva, Switzerland: World Health Organization, 2010.

51. Maarse H, Paulus A, Kuiper G. Supervision in social health insurance: a four country study. Health Policy 2005;71:333-46.

52. Mathauer I, Nicolle E. A global overview of health insurance administrative costs: what are the reasons for variations found? Health Policy 2011;102(2-3):235-46.

53. Wang HQ, Liu ZH, Zhang YZ, et al. Integration of current identitybased district-varied health insurance schemes in China: implications and challenges. Front Med 2012;6:79-84.

54. Tian Z. Existing problems and countermeasures of the integration of medical insurance for urban and rural residents. Administration Reform 2015;02:36-9.

55. Wang $X$, Zheng $A, \mathrm{He} X$, et al. Integration of rural and urban healthcare insurance schemes in China: an empirical research. $B M C$ Health Serv Res 2014;14:1-10. 